An assichous and comparative study of these sources will serve multiple important functions. In addition to bringing researchers in allied fields of dental anthropology up-to-date on current progress and controversy in the field of hominoid dental growth, an in-depth survey of this stimulating literature should provide us with welcome, challenging, and entertaining diversions from the miserable climatic extremes around us.

'I will provide a detailed review of this volume in the Spring issue of the Dental Anthropology Newsletter.

\title{
REFERENCES
}

Macho GA, and Wood BA (1995) The role of time and timing in hominoid dental evolution. Evolutionary Anthropology. 4(I):17-3 1 .

Moggi-Cecchi, J (1995) Aspects of Dental Biology: Palaeontology, Anthropology, and Evolution. Florence: International Institute for the Study of Man.

Primate Tooth formation: A Symposicm. (1991) Am. J. Phys. Anthropol. 86(2):107-309.

Recent Developments in Hominoid Ontogeny. (1996) Am. J. Phys. Anthropol. 99(l):1-220.

\section{PREMOLAR NUMBERING AND AGENESIS IN PRIMATES}

\section{GRAM P. JONES}

Department of Anthropology, Arizona Sfate University; Box 872402 Tempe, AZ 85287-2402, U.S.A.

Over the millions of years that have passed since mammals first appeared during the late Mesozoic, tooth number increased in a few lineages, but generally the primitive mammalian dental formula of 3-1-4-3 was retained or reduced. Primates show a reduction in tooth number through time, with the premolar being the most variable tooth in both size, morphology, and number (James, 1960). All extant primates exhibit a reduction in the primitive number of premolars. Old World anthropoids, including humans, possess a 2-1-2-3 dental formula, with the third incisor and first and second premolars considered to be the reeth that have been lost (Tome, 1889; Leche, 1895). The scope of this article is 1) to review the literature and trace the origin and reasoning for numbering premolars in Old World primates as P3 and P4 in the anthropological literature ratber than as $\mathrm{P} 1$ and $\mathrm{P} 2$; and 2) to briefly discuss premolar agenesis in modern humans.

\section{ORIGIN AND REASONING FOR NUMBERING PREMOLARS IN OLD WORLD PRIMATES}

Heterodont dentition can be traced back to the early Triassic order of Pantotheria whose members possessed simple precanines, a true canine, and postcanines (Osborn, 1973). The therian Thrinaxodon is believed to lie close to the line of mammalian evolution. Thrinaxodon exhibits seven postcanines that become increasingly complex posteriorly. Early Tertiary eutherians cormmonly possessed the dental formula 3-1-4-3 with a larger tooth number occurring only in specialized mammals, such as the toothed whales, porpoises, sirens, and the giant sloth. Prototherians exhibit a 5-1-3-4/4-1-3-4 dental formula or a reduction, but never 3-I4-3 as in the eutherians (Gregory, 1951).

De Blainville (1839) attempted to trace mammalian evolution based on tooth morphology. However, as Owen (1840-45) pointed out, the tooth that is caniniform in one species may be incisiform in another. Owen originated the present classification of teeth based on their position and mode of succession and wrote dental formulae for many of the known vertebrates of his time. Like Owen, Tome (1889) classified teeth in relation to other parts of the body, and also in their relation to one another. He defined premolars as those anterior to the molars and having deciduous precursors. Yet, he points out that they are not always displaced in marsupials. Tome observed that usually the first premolar is lost, except in bears and some bats where P2 and P3 are lost instead.

A major assumption in the determination of which tooth is lost is that the last to develop is the most variable, and therefore, the first to be lost. According to Leche's (1896) rule, from the initial cheek tooth forwards, the first buds produce the largest teeth, while retarded buds lead to the smallest teeth. Embryological studies reveal the tooth bud sequence for the mole Talpa (Sicher, 1916) and most insectivores (Osborne, 1973), which retain the primitive dental formulae, is $i^{1}-i^{2}-i^{3}-c-p^{4}-p^{3}-p^{2}-p^{1}-M^{1}-M^{2}-M^{3}$.

This sequence has flipped around for Tupia (Kindahl, 1957) and Tarsius (Greiner, 1929) with $\mathrm{p}^{3}$ preceding $\mathrm{p}^{4}$, although $\mathrm{p}^{2}$ continues to erupts later. In Pan and Homo $\mathrm{p}^{3}$ also precedes $\mathrm{p}^{4}$ (Schour and Massler, 1941), but $\mathrm{p}^{4}$ generally precedes $\mathrm{p}^{3}$ in Gorilla (Clements and Zuckerman, 1953; Beynon et al, 1991). In the earliest embryos of which rooth formation is evident; il, $\mathrm{cl}$, and $\mathrm{p} 4$ are already present and referred to as the incisor, 
canine, and molar determinants, respectively. The fourth deciduous molar is probably the ancestral molar determinant. Eutherians, with reduced postcanine dentitions, differ only in that the penultimate deciduous molar may sometimes be the molar determinant (Osbom, 1973).

Reconstructions of developing insectivore dentitions show the molar region grows: 1) by interstitial growth between the canine and molar determinants, which provides space for the deciduous molars, and later the premolars, to be initiated in sequence forward; and 2) by expansion posteriorly, which provides space for the permanent molars to be initiated in sequence backwards (Kindahl, 1967; Osborn, 1973). Successive dental papillae derived from a single colony of mesoderm that initially generated $\mathrm{p} 4$ are less able to generate the paradigm molar shape horizontally in the succeeding deciduous molars, and even less so vertically in the premolars (Osbom, 1973).

The permanent molars are sequentially initiated in newly differentiated mesoderm behind the molar determinant. Therefore, each has a shape closer to the paradigm molar than the premolars. In insectivores that "retain" the primitive dental formula, pl is retained throughout life and is never replaced by a successor. This observation lead Kindahl (1967) to assume that reduction of PI begins witb the disappearance of the successor, and not with the deciduous tooth as contended by Leche (1895).

Primates appear early in mammalian history, surfacing in North American deposits dating back to the late Cretaceous. Purgatorius is considered to be the basal stock from which all later primates descended (Van Valen, 1994). However, early protoprimates may have arisen from one or more separate insectivore lineages (Gingerich, 1976). P. ceratops, the earliest specimen, is represented by a single right $\mathrm{M}_{2}$. It is considered to be a more primitive form of $P$. unio, but they may comprise only one species (Van Valen and Sloan, 1965; Van Valen, 1994). Direct evidence exists for $P$. unio having possessed one canine, four premolars, and three molars in each quadrant, but its retention of three incisors is inferred from later specimens referred to the Plesiadapidae, Carpolestidae, Saxonellidae, and Palaechthonidae (Clemens, 1974; Van Valen, 1994).

Polymorphisms in tooth number are seen in many of the Plesiadapidae and are believed to be characteristic of most of the early protoprimates (Gingerich, 1976; Van Valen, 1994). Reduction in the number of anterior premolars occured independently in Pronothodectes, Nannodectes, Plesiadapis, Chiromyoides, and Platychoerops and is believed to be related to the rapid size increase of 11 (Gingerich, 1976). Carpolestidae evolved an enlarged plagiaulacoid P4 with up to five cusps in its extreme that is correlated with P1 agenesis (Fox, 1994). Saxonella creptaturae is uniquely characterized by having a P3 that is much larger than P4, accompanied by the loss of P1 and P2 (Fox, 1984).

The reduction of premolars from the typical eutherian number with $\mathrm{P} 1$ and $\mathrm{P} 2$ being the teeth lost is seen throughout the early primate fossil record and is justifiable on the basis of functional fields. The pastcanines constitute a single integrated puncturing, shearing, and grinding unit. The loss of P3 and P4 would disrupt the functional integration of this unit whereas the loss of the anterior premolars would not (Gingerich, 1976).

Any similarities between the earlier Paleocene representatives of the primate order and the euprimates are considered to be homoplastic. The exception is Purgatorius, which is the only taxon known to retain four premolars in both jaws, a condition that links it with the early prosinians (Van Valen, 1994). The Omomyidae, ancestors to the Tarsiformes, retained four mandibular premolars (Williams and Covert, 1994), while the Adapidae, ancestral to the Lemuriformes, retained four premolars in both jaws (Gingerich, 1976). Like the earlier plesiadapids, an increase in the size of 11 in the Lemuriformes is associated with a loss of PI. $P_{2}$ takes over the function of $C_{1}$ as it is integrated into the tooth comb. As larger canines evolved in the anthropoids, the anterior premolars were displaced by diastemas to accommodate the larger canines, and $P_{2}$ or $P_{3}$ were anterolaterally extended to function as hones for $C^{\prime}$ (Simons, 1972). The second premolar is seen for the last time in the catarrhines at around 40 myr ago in southern Asia in the parapithecine Amphipithecus mogaungensis which may be ancestral to both the New and Old World monkeys (Ciochon et al., 1985).

\section{AGENESIS}

Polymorphisms in premolar tooth number occur throughout the primate line with agenesis occurring most often in the anterior region. However, humans deviate from the typical mammalian pattern with reduction usually taking place from the last premolar forward (Brekhus et al., 1944; Garn et al., 1962; Müller et al., 1970; Baum and Cohen, 1971). Dental agenesis (Table 1) is rare in the cercopithecoids (1.8\%) and pongids (1.0\%) compared to humans ( $11.1 \%$ ), with monkeys and apes exhibiting a bigher frequency of agenesis only in the 
TABLE 1. Dental Agenesis in Old World Primates

\begin{tabular}{|c|c|c|c|c|c|}
\hline & $\begin{array}{l}\text { Number of } \\
\text { Individuals }\end{array}$ & Incisors & Premolars & Molars & Total \\
\hline \multicolumn{6}{|c|}{ Cercopithecoidea } \\
\hline Colobus & 140 & - & $5(3.6)$ & $6(4.3)$ & $11(7.9)$ \\
\hline Presbytis & 100 & $1(1.0)$ & - & - & $1(1.0)$ \\
\hline Cercopithecus & 350 & - & $1(0.3)$ & $3(0.9\rangle$ & $4(1.0)$ \\
\hline Macaca & 350 & - & - & - & -- \\
\hline Papio & 38 & $2(5.3)$ & - & - & $2(5.3)$ \\
\hline Total & 978 & $3(0.3)$ & $6(0.6)$ & $9(0.9)$ & $18(1.8)$ \\
\hline \multicolumn{6}{|l|}{ Ponginae } \\
\hline Gorilla & 190 & $\ldots$ & $1(0.5)$ & $\ldots$ & $1(0.5)$ \\
\hline$P_{a n}$ & 100 & $\cdots$ & $1(1.0)$ & $2(2.0)$ & $3(3.0)$ \\
\hline Pongo & 100 & - & $\cdots$ & $\ldots$ & - \\
\hline Total & 390 & - & $2(0.5)$ & $2(0.5)$ & $4(1.0)$ \\
\hline \multicolumn{6}{|l|}{ Hominidae } \\
\hline Europcans & 4000 & $12(0.3)$ & $5(0.1)$ & $259(6.5)$ & $276(6.9)$ \\
\hline Africans & 1000 & $25(2.5)$ & $10(1.0)$ & $247(24.7)$ & $282(28.2)$ \\
\hline Total & 5000 & $37(0.7)$ & $15(0.3)$ & $506(10.1)$ & $558(11.1)$ \\
\hline
\end{tabular}

Values $=$ number with percentage incidence in brackets. No agenesis was found in the canines. (After Lavelle and Moore, 1973) premolar region (Lavelle and Moore, 1973). Premolar agenesis is generally more common in the mandibular region for all three groups although Brekhus et al. (1944) found the frequencies to be sliglitly higher in the maxillary region for humans.

Dental agenesis in modem humans is commonly correlated with the reduction of the maxillomandibular region due to the high incidence of agenesis of M3 at the distal end of the dental arch and $\mathrm{I}^{2}$ at the mesial aspect (Schultz, 1932; Butler, 1963; Lavelle and Moore, 1973). However, this does not adequately explain the absence of P4 (Brekhus et al,, 1944).

In a comparison of the cercopithecoid, pongid, and human data cited in Lavelle and Moore's study on dental agenesis, largesample z-tests of the population proportion exhibiting tootl agenesis were calculated both for molar and premolar frequencies between the primate groups (no comparison could be made for incisor agenesis due to a lack of comparative data for the great apes). A significant difference was not found between the monkeys and apes in the frequencies of molar agenesis, but significant differences were detected between both the monkeys and humans and the apes and humans $(\mathrm{p}<.001)$. No significant differences were found between any of the groups in regards to premolar agenesis frequencies, suggesting that while molar agenesis may be related to a reduction in the jaw, premolar agenesis is not.

The suggestion that agenesis is related to dental arch reduction in modem humans is not bome out by other lines of evidence. Eskimo populations with large dental arches (Pedersen, 1949) and more prognathous African populations (Lavelle and Moore, 1973) often exhibit a reduction in the third molar region. Brekhus et al. (1944) found little correlation between dental arch size and the number of teeth, citing evidence of agenesis and the retention of large spaces between the teeth in small jaws, agenesis and crowded teeth in small jaws, and crowded teeth in large jaws in individuals within the same families. Reduction in M3 was observed to be accompanied by a reduction in other teeth in $94.7 \%$ of the cases of molar agenesis that Brekhus et al. examined, and multiple deficiencies were seen in nearly half of all cases of agenesis.

Suggestions that tooth size reduction and agenesis are correlated (Butler, 1939; Garn et al., 1963) are not supported by a study that revealed a lack of correlation between the mesiodistal and buccolingual diameters of teeth (Baum and Cohen, 1971). Calcagno and Gibson (1988) suggest that if the maxillomandibular region is undergoing reduction or fewer teeth are needed in modem humans, then positive selection for a reduction in tooth number would be more economical than a reduction in tooth size whereby teeth would wear more quickly. In a clinical study by Brekhus et al. (1944), observed frequencies of various combinations of $\mathrm{l}^{2}, \mathrm{P} 4$, and M3 agenesis far exceeded the expected frequencies, and it was suggested that directional evolution is indeed occurring and reduction in tooth size is merely coexistent.

\section{CONCLUSIONS}

The present system of numbering teeth in mammals based on their position, relation to other teeth, and mode of succession in the paleontological literature dates back to the mid-nineteenth century (Owen, 1840-45). Premolars are counted from the molar region forwards in most veterinary literature due to the stability of the fourth premolar in most mammals (Peyer, 1968). It would appear logical to number the premolars in sequence from the most posterior premolar forwards based on the typical order of their development in mammals. However, this system would present problems with the reversed developmental sequences seen in the tree shrew and extant primates. 
That the anterior premolars are the ones that have been lost in primates is evidenced in the fossil record, where the missing teeth are replaced by diastemas and the premolars show a reduction in size from back to front. Agenesis of $\mathrm{P} 4$ in association with $\mathrm{I}^{2}$ and M3 in modern humans occurs more often than would be expected due to chance alone. This type of agenesis is thought to be an autapomorphic feature of human evolution in conjunction with a reduction of the maxillomandibular region due to natural selection (Brekhus et al., 1944; Lavelle and Moore, 1973; Calcagno and Gibson, 1988). Fourth premolar agenesis is not unique to humans, however (Lavelle and Moote, 1973), and it may be a pleiotropic effect associated with third molar agenesis that may be considered unique to modern humans (Brekhus et al., 1944; Gam et al., 1962).

\section{LITERATURE CITED}

Baum BJ, and Cohen MM (1971) Studies on agenesis in the permanent dentition. Am. J. Phys. Anthropol. $35: 125-12$.

Beynon AD, Dean MC, and Reid DJ (1991) Histological study on the chronology of the developing dentition in gorilla and orangutan Am. J. Phys. Anthropol. 86:189-203.

Brekhus PJ, Oliver CP, and Montelius $G$ (1944) A study of the pattem and combination of congenitally missing teeth in man. J. of Dent. Res. 23:117-133.

Butler PM (1939) Studies of the mammalian dentition. Differentiation of the post-canine dentition. Proc. Zool. Soc. Lond. BI09:136.

Butler PM (1963) Tooth morphology and primate evolution. In DR Brochwell (ed): Dental Anthropology. Oxford: Pergamon Press, pp. 1-13.

Calcagno JM, and Gibson KR (1988) Human dental reduction: Natural selection or the probable mutation effect. Am. J. Phys. Anthropol. 77:505-517.

Ciochon R, Savage DE, Tint J, and Maw B (1985) Anthropoid origins in Asia? New discovery of Amphipithecus from the Eocene of Burma. Science 229:756-759.

Clemens WA (1974) Purgatorius, an early paromomyid primate (Mammalia). Science 184:903-905.

Clements EMB, and Zuckeman S (1953) The order of eruption of the permanent teeth in the Hominoidea. Am. J. Phys. Anthropol. 11:313-337.

De Blainville HMD (1839) Ostèographie des Mamifères. '1 A. De l'Ostéographie en génèrai.'

Fox RC (1984) First Nonth American record of the Paleocene primate Saxonella. J. of Paleont. 58:892-894.

Fox RC (1994) The primitive dental formula of the Carpolestidae and its phylogenetic implications. J. of Vert. Paleont. 13:5t6.

Garn SM, Lewis AB, and Vicinus JH (1962) Third molar agenesis and reduction in the number of other teeth. J. Dent. Res. 41:717.

Gam SM, Lewis AB, and Kerewsky RS (1963) Third molar agenesis and size reduction of the remaining teeth. Nature 200: 488 489.

Gingerich PD (1976) Cranial anatomy and evolution of early Tertiary Plesiadapidae (Mammalia, primates). Ann Arbor, Michigan: Museum of Paleontology.

Gregory WK (1951) Evolution emerging, Vol. I. New York: The MacMillan Company.

Greiner E (1929) Zur entwicklungsgeschiche des Gebisses von Tarsius spectrum. Z. Anat. EntwGesch 89;102.

James WW (1960) The jaws and teeth of primates. London: Pitman Medical Publishing Co, Lid.

Kindahl M (1957) On the development of the teeth in Tupaia javanica. Arkiv. Zool. 10: 463-479.

Kindahl ME (1967) Some comparative aspects of the reduction of the permanent molars in the Insectivora. J. Dent. Res. 46:805-808.

Lavelle CLB, and Moore J (1973) The incidence of agenesis and polygenesis in the primate dentition. Am. J. Phys. Anthropol. 38:671-680.

Leche W (1895) Zur Enrwichlungsgeschichte des Zahnsystems der Saügethiere, zugleìch un Beitrag zur Stammeszeschichte dieser Thiergruppe. 1. Ontogenie. Zoologica, Stuttgar, 6, Heft 17, 1.

Leche W (1896) Untersuchungen über des Zahnsystems lebender \& fossiler Halbaffen, Festschr. Gegenbaur, Leipzig 3:125.

Müller TP, Hill IN, Pelersen AC, and Blayney JR (1970) A survey of congenitally missing teeth. J. Am. Dent. Assoc, 81:101107.

Osbom JW (1973) The evolution of dentition. Am. Sci. 61:548-559.

Owen R (1840-45) Odontography; or, a treatise on the comparative anatomy of the ceth. Vol. I. London: H. Bailliere, pp. 298-299.

Pedersen PO (1949) The East Greenland Eskimo dentition. Meddelelser on Gronland.

Peyer B (1968) Comparative odontology. Chicago: University of Chicago Press.

Schour I, and Massler M (1941) The development of the human dentition. J. of Am. Dent. Assoc. 28:1153-1160.

Schultz AH (1932) The hereditary tendency to eliminate the upper lateral incisors. Human Biol. 4:34-40.

Sicher H (1916) Die Entwicklung des Gebisses von Talpa europaea. Arb. Anat. Inst. Wiebaden 54:31.

Simons EL (1972) Primate evolution. New York: The MacMillan Company.

Tome CS (1889) A manual of dental anatomy; human and comparative. 3rd ed. London: J \& A Churchill.

Van Valen LM (1994) The origin of the plesiadapid primates and the nature of Purgatorius. Chicago: Evolutionary Monographs 15.

Van Valen L, and Sloan RE (1965) The earliest primates. Science 150:743-745

Williams BA, and HH Cover (1994) New early Eocene Anaptomorphine primate (Omomyidae) from the Washakie Basin, Wyoming, with comments on the phylogeny and paleobiology of Anaptomorphines. Am. J. Plyss. Anthropol. 93:323-340. 